\title{
Effect of Foliar Application of Banana Pseudostem Sap on Yield of Cowpea (Vigna unguiculata L. Walp.)
}

\author{
W.S.L.V. Fernando and Brintha Karunarathna ${ }^{a}$ \\ Department of Crop Science, Faculty of Agriculture, Eastern University, Sri Lanka \\ ailbrintha@yahoo.co.in or brinthak@esn.ac.lk
}

Keywords: Banana pseudostem sap, inorganic fertilizer, cowpea, foliar spray, pod.

\begin{abstract}
Improved soil fertility is a requirement for enhanced crop production. Combination of inorganic and organic fertilizers improve crop productivity while reduce environmental degradation. An experiment was carried out at Eastern University, Sri Lanka to study the effect of Foliar Application of Banana Pseudostem Sap on Yield of Cowpea (Vigna unguiculata L. Walp.) in sandy regosol. The experiment was laid out in Randomized Complete Block Design having five treatments viz; recommended inorganic fertilizer $\mathrm{N}, \mathrm{P}, \mathrm{K}$ as basal and $\mathrm{N}$ as topdressing (T1), N, P, $1 / 2 \mathrm{~K}$ as basal with recommended $\mathrm{N}$ as topdressing and foliar spray of $1 \%$ $, 3 \%, 5 \%$ and $7 \%$ banana pseudostem sap solution (T2-T5) at $3^{\text {rd }}, 5^{\text {th }}, 7^{\text {th }}$ and $9^{\text {th }}$ week after planting. The results revealed that significant difference $(\mathrm{P}<0.05)$ were noted on number of pods per plant at $1^{\text {st }}$ and $2^{\text {nd }}$ picking. Higher number of pods per plant, maximum pod length and girth were in T2 while low in T1. Sun dried weights of pods and number of seeds per pod were significantly $(\mathrm{P}<0.05)$ varied at each picking. Further, cowpea yield at each picking were higher in T2 compared to tested treatments. The present study suggested that, among the tested treatments $\mathrm{N}, \mathrm{P}, 1 / 2 \mathrm{~K}$ as basal with recommended $\mathrm{N}$ as topdressing and foliar spray of $1 \%$ Pseudostem sap solution at $3^{\text {rd }}, 5^{\text {th }}, 7^{\text {th }}$ and $9^{\text {th }}$ WAP would be the most suitable for cowpea production in sandy regosol.
\end{abstract}

\section{Introduction}

The most dominant crop in the family Leguminoseae is cowpea (Vigna unguiculata L. Walp) which plays significant role in economy of the most of the countries. Farmers prefer to cultivate cowpea due to its drought tolerance features, high protein content, nitrogen fixing ability and wide adaptability. Cowpea has gained more attention recently from consumers due to health beneficial properties, including anti-diabetic, anti-cancer, anti-hyperlipidemic, antiinflammatory and anti-hypertensive properties (Jayathilake et al., 2018). Presently fertilizer has become an essential part in modern agriculture and it is very common that excessive doses of nitrogen and other inorganic fertilizers are applied to vegetable gardens and fields to attain high yield (Baitilwake et al., 2011). Continuous use of these chemical fertilizers depletes essential soil nutrients and minerals that are naturally found in fertile soil. Therefore, substitution of chemical fertilizers by the low cost organic manures is very important for sustainability of agriculture production and maintain of soil fertility for future generation.

Banana is the most important fruit crop widely cultivating in Sri Lanka mainly for fruit purpose. But after the fruit harvest huge quantity of pseudostem is generated as a waste. Pseudostem sap contains essential macro and micro nutrients, growth promoting substances like cytokinin and GA3 (Gibberellic Acid) and it can use as an organic nutritive supplier to the crops for increase their crop growth and yield. This nutritive enriched sap can be applying to the plants 
as the foliar spray to enhance the plant growth and yield, and it is a one of the more cost effective fertilizer can found naturally.

\section{Methodology}

This experiment was carried out to study the impact of foliar spray of banana pseudostem on cowpea yield in sandy regosol. Experiment was carried out using Randomized Complete Block Design. Treatments were;

T1: $\quad$ Recommended N, P and $\mathrm{K}$ as basal and topdressing

T2: $\quad$ Recommended N, P and $1 / 2 \mathrm{~K}$ as basal and topdressing with $1 \%$ pseudostem sap solution

T3: Recommended N, P and $1 / 2 \mathrm{~K}$ as basal and topdressing with 3\% pseudostem sap solution

T4: Recommended N, P and $1 / 2 \mathrm{~K}$ as basal and topdressing with 5\% Pseudostem sap solution

T5: Recommended N, P and $1 / 2 \mathrm{~K}$ as basal and topdressing with 7\% Pseudostem sap solution

The banana (Musa acuminate l.) pseudo stem was collected and it was cut into two pieces and outer sheaths (2-3), damage and dried parts were removed. After the removal of sheaths, it was washed out to remove dust and the tiny materials. Then washed pseudostem was cut in to small pieces $(1 \mathrm{~cm}-5 \mathrm{~cm})$ and chopped by using motor and pistil. Then chopped paste was squeezed in muscling cloth and extraction was filtered. Then insoluble particles of extraction were removed by using centrifugation for $10 \mathrm{mins}$ at 6000rpm (Sharma et al., 2017). 1\%, 3\%, 5\% and $7 \%$ of banana pseudostem sap solutions were prepared by adding $1 \mathrm{ml}, 3 \mathrm{ml}, 5 \mathrm{ml}$ and $7 \mathrm{ml}$ of banana pseudostem saps in to four conical flasks respectively and it was volumerized in to $100 \mathrm{ml}$ by using water. Banana pseudostem sap was sprayed $3^{\text {rd }}, 5^{\text {th }}, 7^{\text {th }}$ and $9^{\text {th }}$ week after planting. $25 \mathrm{ml}$ of banana pseudostem sap solution was applied to each and every plant by using hand spray bottle. All agronomic practices were maintained as per the recommendation of Department of Agriculture, Sri Lanka, except treatments. Yield components were recorded and analysed by using statistical software.

\section{Results and Discussion}

\section{Number of pods per plant}

There was significant difference $(\mathrm{P}<0.05)$ in number of pods per plant at $1^{\text {st }}$ and $2^{\text {nd }}$ pickings were confirmed with $P$ value of $0.020,0.012$ and chi square value of $11.67,12.86$ respectively is shown in table 1 . At $1^{\text {st }}$ picking, the highest number of pods of 6 was observed in T2 and lowest number of pods of 3 was observed in T1. At $2^{\text {nd }}$ picking, the highest number of pods of 8 was observed in T2 and lowest number of pods of 4 was observed in T1 and T4. Foliar application of multi nutrient fertilizer enhanced the number of pods per okra plant than control (Abbasi et al., 2010). Nkaa et al. (2014) noted that the number of pods per plant of the cowpea variety was significantly enhanced by phosphorus foliar application. According to Sandeep et al. (2019) who stated that foliar application of micronutrients treated plants enhanced the number of pods per plant than control. 
Table 1. Number of pods per plant at each picking

\begin{tabular}{|l|l|l|l|}
\hline Treatment & $1^{\text {st }}$ picking & $2^{\text {nd }}$ picking & $3^{\text {rd }}$ picking \\
\hline T1 & 3 & 4 & 4 \\
\hline T2 & 6 & 8 & 6 \\
\hline T3 & 5 & 5 & 4 \\
\hline T4 & 4 & 4 & 5 \\
\hline T5 & 5 & 5 & 4 \\
\hline & & & \\
\hline$P$ value & 0.020 & 0.012 & 0.143 \\
\hline Chi - square & 11.67 & 12.86 & 6.87 \\
\hline
\end{tabular}

\section{Pod length}

here was significant variation $(\mathrm{P}>0.05)$ on average length of the pod at $2^{\text {nd }}$ and $3^{\text {rd }}$ picking by the foliar application of different concentration of banana pseudo stem sap is shown in table 2 . At $2^{\text {nd }}$ and $3^{\text {rd }}$ picking, maximum average length of fruit was obtained in T2 $(17.32 \mathrm{~cm}$ and $17.59 \mathrm{~cm})$ while minimum length of pod was obtained in T1 $(11.77 \mathrm{~cm}$ and $12.47 \mathrm{~cm})$. Banana pseudostem sap contains sufficient amount of essential macro and micro nutrients which have direct or indirect effect on pod length may be the reason for longer pod length in sap treated plants compared with control. Similar finding was stated by Rathod et al. (2017) that maximum fruit length and circumference of pomegranate were obtained in application of banana pseudostem sap at $1 \%$.

Table 2. Pod length (cm) at each picking

\begin{tabular}{lcl}
\hline Treatment & $1^{\text {st }}$ picking $2^{\text {nd }}$ picking & $3^{\text {rd }}$ picking \\
\hline T1 & $11.53 \pm 0.1411 .77 \pm 0.07 \mathrm{~d}$ & $12.47 \pm 0.14 \mathrm{~d}$ \\
T2 & $16.65 \pm 0.0917 .32 \pm 0.09 \mathrm{a}$ & $17.59 \pm 0.09 \mathrm{a}$ \\
T3 & $13.60 \pm 0.1414 .27 \pm 0.14 \mathrm{c}$ & $14.54 \pm 0.14 \mathrm{c}$ \\
T4 & $11.82 \pm 2.3014 .99 \pm 0.10 \mathrm{~b}$ & $15.26 \pm 0.10 \mathrm{~b}$ \\
T5 & $13.86 \pm 0.0414 .53 \pm 0.04 \mathrm{c}$ & $14.80 \pm 0.04 \mathrm{c}$ \\
\hline & & \\
\hline F test & $\mathrm{ns} * *$ & $* *$ \\
\hline
\end{tabular}

Value represent mean \pm standard error of four replicates. F test: - ns: not significant; **: $\mathrm{P}<0.01$; Means followed by the same letter in each column are not significantly different according to the Duncan's Multiple Range Test at 5\% level.

\section{Pod girth}

There was no significant difference $(\mathrm{P}>0.05)$ in pod girth at $1^{\text {st }}$ and $2^{\text {nd }}$ picking. However, there was a significant difference in $(\mathrm{P}<0.05)$ pod girth at $3^{\text {rd }}$ picking is shown in table 3 . T2 recorded the maximum pod girth $(2.66 \mathrm{~cm})$ and $\mathrm{T} 1$ recorded the lowest pod girth $(2.01 \mathrm{~cm})$ at $3^{\text {rd }}$ picking. These are in conformity with Sandeep et al. (2019) who stated that pod girth was 
increased by foliar application of micronutrients when compared to control. The maximum increase in the pod girth was recorded in the foliar application of humic acid, zinc and boron in pungent pepper than control (Manas et al., 2014). Mehraj et al. (2015) reported that foliar application of micronutrients increased okra pod girth than control treatment.

Table 3. Pod girth (cm) at each picking

\begin{tabular}{lll}
\hline Treatment & $1^{\text {st }}$ picking $2^{\text {nd }}$ picking & $3^{\text {rd }}$ picking \\
\hline T1 & $2.19 \pm 0.182 .16 \pm 0.17$ & $2.01 \pm 0.19 \mathrm{~b}$ \\
T2 & $2.62 \pm 0.052 .71 \pm 0.09$ & $2.66 \pm 0.05 \mathrm{a}$ \\
T3 & $2.47 \pm 0.072 .36 \pm 0.08$ & $2.27 \pm 0.06 \mathrm{~b}$ \\
T4 & $2.29 \pm 0.072 .11 \pm 0.17$ & $2.33 \pm 0.02 \mathrm{ba}$ \\
T5 & $2.31 \pm 0.062 .23 \pm 0.07$ & $2.35 \pm 0.07 \mathrm{ba}$ \\
& & \\
\hline F test & $\mathrm{nsns}$ & $*$ \\
\hline
\end{tabular}

Value represent mean \pm standard error of four replicates. $\mathrm{F}$ test: - ns: not significant; *: $\mathrm{P}<0.05$ Means followed by the same letter in each column are not significantly different according to the Duncan's Multiple Range Test at 5\% level.

\section{Number of seeds per pod}

Application of different concentration of banana pseudo stem sap significantly influence $(\mathrm{P}<0.05)$ the number of seeds per pod is confirmed with $P$ values 0.040 and chi square values 10.00 at $1^{\text {st }}, 2^{\text {nd }}$ and $3^{\text {rd }}$ picking (Table 4). Maximum numbers of seed were observed in $\mathrm{T} 2$ and minimum numbers of seed were observed in T1. Sharifi et al. (2018) reported that number of seed per fruit or seed yield was significantly influenced by foliar application of water soluble fertilizer as the foliar application and significantly higher seed yield recorded with application of foliar application of water soluble fertilizer at $2 \%$ at flowering and pod filling stages while lowest data obtained in control treatment in soybean.

Table 4. Number of seeds per pod at each picking

\begin{tabular}{llll}
\hline Treatment & $1^{\text {st }}$ picking & $2^{\text {nd }}$ picking & $3^{\text {rd }}$ picking \\
\hline T1 & 6 & 8 & 9 \\
T2 & 11 & 13 & 14 \\
T3 & 9 & 11 & 12 \\
T4 & 10 & 12 & 13 \\
T5 & 8 & 10 & 12 \\
\hline$P$ value & 0.040 & 0.040 & 0.040 \\
Chi - square & 10.00 & 10.00 & 10.00 \\
\hline
\end{tabular}




\section{Sun dried weight per pod}

Table 5 represents the different concentration of banana pseudo stem sap application on sun dried weight of pods. At all the picking stages, maximum dry weight of pod were observed in $\mathrm{T} 2$ and minimum fresh weight of pod was observed in T1. At $1^{\text {st }}, 2^{\text {nd }}$ and $3^{\text {rd }}$ picking maximum weight of pod was observed in T2 $(1.82 \mathrm{~g}, 2.30 \mathrm{~g}$ and $2.49 \mathrm{~g})$ followed by T3 $(1.55 \mathrm{~g}, 2.03 \mathrm{~g}$ and $2.22 \mathrm{~g}$ ) while lowest weight of pod was observed in T1 (1.38 g, $1.86 \mathrm{~g}$ and $2.05 \mathrm{~g})$. Rathod et al. (2017) reported the evident that significantly maximum fruit weight was obtained in banana pseudostem sap at $1 \%$ because banana pseudostem sap contain the $\mathrm{N}$ and $\mathrm{K}$ in higher rates and these elements increased the efficiency of metabolic process of the trees and encouraged the growth of pomegranate. Similar findings were obtained by Patil et al. (2014) in garlic. Deore et al. (2010) reported experiment data in chili, revealed that the foliar application of novel organic liquid fertilizer $2 \%$ shows the maximum fruit weight $(\mathrm{g})$.

Table 5. Sun dried weight (g) of pod at each picking

\begin{tabular}{llll}
\hline Treatment & $1^{\text {st }}$ picking & $2^{\text {nd }}$ picking & $3^{\text {rd }}$ picking \\
\hline $\mathrm{T} 1$ & $1.38 \pm 0.04 \mathrm{~d}$ & $1.86 \pm 0.04 \mathrm{~d}$ & $2.05 \pm 0.04 \mathrm{~d}$ \\
$\mathrm{~T} 2$ & $1.82 \pm 0.04 \mathrm{a}$ & $2.30 \pm 0.04 \mathrm{a}$ & $2.49 \pm 0.04 \mathrm{a}$ \\
$\mathrm{T} 3$ & $1.55 \pm 0.04 \mathrm{~b}$ & $2.03 \pm 0.04 \mathrm{~b}$ & $2.22 \pm 0.04 \mathrm{~b}$ \\
$\mathrm{~T} 4$ & $1.52 \pm 0.03 \mathrm{cb}$ & $2.00 \pm 0.03 \mathrm{cb}$ & $2.19 \pm 0.03 \mathrm{cb}$ \\
T5 & $1.43 \pm 0.01 \mathrm{~cd}$ & $1.91 \pm 0.01 \mathrm{~cd}$ & $2.05 \pm 0.01 \mathrm{~d}$ \\
\hline F test & $* *$ & $* *$ & $* *$ \\
\hline
\end{tabular}

Value represent mean \pm standard error of four replicates. $\mathrm{F}$ test: - **: $\mathrm{P}<0.01$; Means followed by the same letter in each column are not significantly different according to the Duncan's Multiple Range Test at 5\% level.

\section{Cowpea yield}

It was found that, there were significant differences $(\mathrm{P}<0.01)$ at $1^{\text {st }}, 2^{\text {nd }}$ and $3^{\text {rd }}$ picking is shown in table 6 . At $1^{\text {st }}, 2^{\text {nd }}$ and $3^{\text {rd }}$ picking, the highest mean value for total seed yield was obtained in T2 (1.94 tons/ha, 3.04 tons/ha, 3.03 tons/ha) while, minimum mean value was obtained in T1 (0.44 tons/ha, 0.73 tons/ha, 1.01 tons/ha). However, there were no significant differences $(\mathrm{P}>0.05)$ among treatments except $\mathrm{T} 2$ and $\mathrm{T} 1$ at $1^{\text {st }}$ and $2^{\text {nd }}$ picking. Farouk and Amany (2012) stated that pod yield per plant, seed quality and total seed yield significantly increased with foliar application of chitosan, especially at $250 \mathrm{mg} / \mathrm{l}$. 
Table 6. Total seed yield (tons/ha) at each picking

\begin{tabular}{llll}
\hline Treatment & $1^{\text {st }}$ picking & $2^{\text {nd }}$ picking & $3^{\text {rd }}$ picking \\
\hline T1 & $0.44 \pm 0.04 \mathrm{c}$ & $0.73 \pm 0.07 \mathrm{c}$ & $1.01 \pm 0.12 \mathrm{c}$ \\
$\mathrm{T} 2$ & $1.94 \pm 0.17 \mathrm{a}$ & $3.04 \pm 0.05 \mathrm{a}$ & $3.03 \pm 0.20 \mathrm{a}$ \\
$\mathrm{T} 3$ & $1.01 \pm 0.03 \mathrm{~b}$ & $1.32 \pm 0.13 \mathrm{~b}$ & $1.47 \pm 0.12 \mathrm{cb}$ \\
$\mathrm{T} 4$ & $0.93 \mathrm{~b} \pm 0.06 \mathrm{~b}$ & $1.37 \pm 0.10 \mathrm{~b}$ & $1.78 \pm 0.09 \mathrm{~b}$ \\
$\mathrm{~T} 5$ & $0.95 \pm 0.10 \mathrm{~b}$ & $1.47 \pm 0.12 \mathrm{~b}$ & $1.49 \pm 0.13 \mathrm{cb}$ \\
& & & \\
\hline F test & $* *$ & $* *$ & $* *$ \\
\hline
\end{tabular}

Value represent mean \pm standard error of four replicates. $\mathrm{F}$ test: - **: $\mathrm{P}<0.01$; Means followed by the same letter in each column are not significantly different according to the Duncan's Multiple Range Test at 5\% level.

\section{Conclusion}

The results revealed that there was significant difference $(\mathrm{P}<0.05)$ were observed in number of pod, $1^{\text {st }}$ and $2^{\text {nd }}$ picking, pod length at $2^{\text {nd }}$ and $3^{\text {rd }}$ picking and pod girth at $3^{\text {rd }}$ picking among treatments. Maximum length and girth of pod was observed in T2 while minimum length and girth of pod was observed in T1. Number of seeds per pod at each picking had significant variation $(\mathrm{P}<0.05)$ and it was high in sap treated plants compared with control. Sun dried weight of cowpea pod was significantly influenced by the banana pseudo stem sap application. All three pickings, maximum sun dried weight of pod was observed in T2 while lowest sun dried weight of pod was observed in T1. According to cowpea yield, highest cowpea seeds were obtained in T2 and low in control. Application of different concentration of banana pseudostem sap increased yield component of cowpea grown in sandy regosol compared to recommended inorganic fertilizer. The present study concluded that among the tested treatments $\mathrm{N}, \mathrm{P}, 1 / 2 \mathrm{~K}$ as basal with recommended $\mathrm{N}$ as topdressing and foliar spray of $1 \%$ Pseudostem sap solution at $3^{\text {rd }}$, $5^{\text {th }}, 7^{\text {th }}$ and $9^{\text {th }}$ WAP would be the most suitable for cowpea production in sandy regosol.

\section{References}

[1] Abbasi, F. F., Baloch, M. A., Zia-ul-hassan., K. H. Wagan, K. H., Shah, A. N. and Rajpar, I. (2010). Growth and yield of okra under foliar application of some new multinutrient fertilizer products. Pakistan Journal of Agriculture, Agricultural Engineering and Veterinary Science. 26(2): 11-18.

[2] Baitilwake, M. A., Bolle, S. D., Salomez, J., Mrema, J. P. and Neve, S. D. (2011). Effects of manure nitrogen on vegetables' yield and nitrogen efficiency in Tanzania. International Journal of Plant Production. 5(4): 417-430.

[3] Deore, G. B., Limaye, A. S., Shinde, B. M. and Laware, S. L. (2010). Effect of Novel Organic Liquid Fertilizer on growth and yield in chilli (Capsicum annum L.). Asian Journal of Experimental Biological Sciences. 1(4): 15-19. 
[4] Farouk, S. and Amany, A. R. (2012). Improving growth and yield of cowpea by foliar application of chitosan under water stress. Egyptian Journal of Biology. 14: 14-26.

[5] Jayathilake, C., Visvanathan, R., Deen, A., Bangamuwage, R., Jayawardana, B. C., Nammic, S.and Liyanage, R. (2018). Cowpea an overview on its nutritional facts and health benefits.Journal of the Science of Food and Agriculture. 99(8): 1-18.

[6] Manas, D., Bandopadhyay, P. K., Chakravarty, A., Pal, S. and Bhattacharya, A. (2014). Effect of foliar application of humic acid, zinc and boron on biochemical changes related to the productivity of pungent pepper (Capsicum annuum L.). African Journal of Plant Science. 8(6):320 - 335.

[7] Mehraj, H., Taufique, T., Mandal, M. S. H., Sikder, R. K. and Uddin, A. J. (2015) Foliar Feeding of Micronutrient Mixtures on Growth and Yield of Okra (Abelmoschus esculentus). American Eurasian Journal of Agriculture \& Environment Science. 15(11): 2124 - 2129.

[8] Nkaa, F. A., Nwokeocha, O. W. and Ihuoma, O. (2014). Effect of Phosphorus fertilizer on growth and yield of cowpea (Vigna unguiculata). Journal of Pharmacy and Biological Sciences. 9(5): 74-82.

[9] Patil, T. D., Kolambe, B. N., Patil, R. G. and Bafana, A. M. (2014). Effect of rates of castor cake and banana pseudostem sap on yield and quality attributing characters of organically grown garlic (Allium sativum L.). Bioinfolet. 11(1): 100 - 104.

[10] Rathod, M. J., Ramdevputra, M. V., Nurbhanej, K. H. and Patel, M. S. (2017). Effect of ethrel and banana pseudostem sap on fruit yield and yield attributes of pomegranate (Punica granatum L.) cv. Bhagwa. International Journal of Chemical Studies. 5(5): 392396.

[11] Rathod, M. J., Ramdevputra, M. V., Nurbhanej, K. H. and Patel, M. S. (2017). Effect of ethrel and banana pseudostem sap on fruit yield and yield attributes of pomegranate (Punica granatum L.) cv. Bhagwa. International Journal of Chemical Studies.5(5):392396.

[12] Sandeep, G., Swaminathan, V., Paramaguru, P. and Janaki, D. (2019). Effect of foliar application of micronutrients on growth, yield, and quality of annual moringa (Moringa oleifera Lam.). Journal of Pharmacognosy and Phytochemistry. 8(3): 363-367

[13] Sharifi, S. K., Lalitha, B. S., Qasimullah, R., Kumar, G. K. P. and Manjanagoud, S. S. (2018). Effect of Foliar Application of Water Soluble Fertilizer on Growth and Yield of Soybean (Glycine max L. Merrill). International Journal of Pure and Applied Bioscience. 6(5): 766-770. 